\title{
Complementary Possibilities in Human-Nature Interaction in an Urban Context - a case study: Darband River-Valley in Tehran
}

\author{
Sanaz Shobeiri ${ }^{1}$
}

$1 \mathrm{PhD}$ in Urban Development and Regeneration, School of Architecture and the Built Environment, University of Westminster, London, United Kingdom.

\begin{tabular}{|c|c|}
\hline ARTICLE INFO & ABSTRACT \\
\hline $\begin{array}{l}\text { Keywords: } \\
\text { natural structures; river- } \\
\text { valley; social attitudes; } \\
\text { sustainability; water }\end{array}$ & $\begin{array}{l}\text { One of the current key challenges concerning a city's natural } \\
\text { structures is to identify how the potential and existing methods of } \\
\text { human-nature interaction can complement each other in a way that } \\
\text { results in achieving sustainability in the full sense of the concept. In } \\
\text { other words, it is necessary to define a subtle and nuanced set of } \\
\text { complementary possibilities between human beings and nature while } \\
\text { investigating metropolitan landscape structures. To this end, this } \\
\text { paper aims to elaborate on the natural structures of the river-valleys } \\
\text { of Tehran with a specific consideration of one river-valley called } \\
\text { Darband. With a length of 33km through the urban and peri-urban } \\
\text { areas of Tehran from the northernmost to the southernmost points, } \\
\text { Darband river-valley provides a wide range of potentials - as well as } \\
\text { problems - in terms of human-nature interaction in its } \\
\text { neighbourhoods. This spectrum of potential includes mainly: inner- } \\
\text { city local and medium-sized parks and the tendency for } \\
\text { neighbourhood-scale communication; urban spaces of squares and } \\
\text { streets and the disappearing history; big parks and unconstructed } \\
\text { pieces of land and social attitudes associated with specific days; } \\
\text { mountainous recreational areas; and bridges as landscape in transit as } \\
\text { well as acting as pause points. In this design- and context-based } \\
\text { research, the applied methodology consists of a review of the related } \\
\text { literature, direct observation, interviews, and design and planning. In } \\
\text { this paper, the focus is primarily on socio-cultural aspects of } \\
\text { sustainability, and the environmental aspect is studied as an affiliated } \\
\text { and interdependent aspect. }\end{array}$ \\
\hline
\end{tabular}

\section{Introduction}

One of the most important current issues in cities worldwide is that a significant proportion of areas that were on the outskirts of cities have been transformed into urban areas. Consequently, a considerable part of the landscape structures that once outskirted cities or were in peri-urban areas have been converted into the cities' natural structures (Anvar, 2011; Banimasoud, 2009; Behzadfar, 2007; Municipality of Tehran, 2015). Thus, in order to achieve sustainable projects and designs for these natural structures, they need to be considered as urban-scale projects. In other

\footnotetext{
$\square$ Corresponding Author E-Mail Address: sanaz.shobeiri@my.westminster.ac.uk
} 
words, the relationship between human beings and nature - or, more precisely between a city's natural structures and its citizens - needs to be studied in a multidisciplinary and interdisciplinary arena, incorporating the urban-scale challenges relating to these natural structures. This arena involves various fields of study such as urban design, urban planning, landscape design, ecological studies, sociology, anthropology, cultural studies and psychology.

This paper focuses mainly on one case study in order to consider the relationship between a city's natural structures and its citizens. Darband river-valley in Tehran, with a length of $33 \mathrm{~km}$ flowing through urban and peri-urban areas, has been selected as the indicative continuous landscape structure of Tehran in order to study the interaction between Tehranians and Tehran's natural structures. To this end, this paper defines design and planning strategies that cater to the needs and potentials of the selected river-valley and Tehranian residents. These design and planning strategies need to be defined in complementary ways in order to achieve an integrated whole in terms of the sustainable human-nature relationship.

The strategies are categorised into five sections, as follows: inner-city local and medium-sized parks and the tendency for neighbourhood-scale communication; urban spaces in the form of squares and streets and the disappearing history; big parks and unconstructed pieces of land and social attitudes associated with specific days; mountainous recreational areas; and bridges as landscape in transit as well as acting as pause points. These five sections are discussed in detail in this paper in sections 7.1-7.5.

\section{Methodology}

In order to investigate the complementary possibilities along the $33 \mathrm{~km}$-long river-valley of Darband in this research, it is necessary to apply a combination of methods. The series of applied methods in this design- and context-based research include the literature review, direct observation, interviews, and design and planning. The methods and how they complement each other to respond to the main question of this paper are explained in this section.

\subsection{Literature review}

In order to study the human-nature interaction in the context of Tehran, and with a focus on Darband river-valley, a literature review and related analysis is necessary. The reasons for the application of this method are three-fold. First, it is necessary to review the literature relating to the city of Tehran and the gradual and drastic changes it has undergone since becoming the capital city in 1794. This review clarifies the key characteristics of the context and, hence, presents the processes of change in the structure and form of Tehran and its river-valleys.

Second, in order to investigate the present and future needs, as well as the problems and potentials of the river-valleys and Tehranian users, it is necessary to identify and review the literature relating to the implemented projects. A review of the literature on the river-valleys reveals that three linear parks and four mountainous recreational areas are the principal projects that have been implemented along specific lengths of some of the seven main river-valleys. However, no previous studies have investigated how Tehranians interact with the existing natural structures of the river-valleys in these projects. Addressing this gap in the literature necessitates the use of the methods of direct observation and interviews, which are discussed below.

Third, in order to investigate the potentials and problems relating to the interaction between Tehranians and the Darband river-valley, it is necessary to study the detailed characteristics of this 
river-valley and its current situation. A review of the literature relating to this river-valley clarifies some of its key features on an urban scale and the existing variety in the context of its neighbourhood. These features need to be studied in depth within the context of the current situation in Tehran. As a result, the supplementary method of direct observation is applied to the whole length of Darband river-valley (33km). As explained by Finn (2005), a critical evaluation that is carried out through the process of revising and updating the literature review at different stages of the research can result in providing in-depth information on the context and background of the study.

\subsection{Direct observation}

Qualitative-based analysis through direct observation is ' $\ldots$ an interpretive naturalistic approach to its subject matter ... [it studies] things in their natural settings, attempting to make sense of, or interpret, phenomena in terms of meanings people bring to them' (Groat \& Wang, 2002, p. 176). The focus on natural settings in the method of direct observation results in the study of the non-interfered status (Groat \& Wang, 2002). Considering the second and third aspects above (in the literature review), direct observation is necessary to study the natural settings of humannature interaction in particular in the river-valleys in Tehran in terms of the two different following aspects and two types of area of the implemented projects of the linear parks and the mountainous recreational areas.

First - and relevant, following the second aspect above - direct observation of the implemented projects within the linear parks and mountainous recreational areas reveals how Tehranian citizens currently interact with the river-valleys, how they differentiate between a park and a mountainous area, and how their expectations, likes and dislikes differ in these two types of area. Direct observation also reveals the current problems and needs of the river-valleys, such as water pollution, as well as the potentials of these natural structures for future projects. In order to consider the seasonal effects, the direct observation was carried out in different seasons in 2012 and 2013 and at different hours of the day from $10 \mathrm{am}-2 \mathrm{pm}$ and $6 \mathrm{pm}-1 \mathrm{am}$.

Second - and relevant, following the third aspect above - in order to investigate the neighbourhood surrounding the case study river-valley in depth, a direct appraisal was performed along the whole length of Darband river-valley (over $33 \mathrm{~km}$ ). In other words, although the review of the literature relating to Darband river-valley clarifies the general features of this area, direct observation elaborates on the current characteristics of the neighbourhood area of this case study river-valley. The type and quality of the residential area in the river's neighbourhood, the quality of the water, and the characteristics of the neighbourhood streets are a few examples of the details that are revealed through direct appraisal of Darband river-valley.

\subsection{Interviews}

Investigating the present and future needs, problems and potentials associated with the interaction between Tehranians and the river-valleys through direct observation has raised the question of whether the current options for interaction are based on Tehranians' interests. In other words, there is a concern regarding whether the existing possibilities for interaction are based on Tehranian users' desires or whether people have adapted themselves to the current options because these are the only possible opportunities at the moment. Hence, direct observation as a requisite method needs to be accompanied by another method in order to study the hidden aspects of this 
interaction. This complementary method investigates the extent to which the desires of Tehranians are fulfilled in the three parks and the four mountainous recreational areas of Tehran.

The primary method used to study the abovementioned invisible aspects is the semi-structured interview. As explained by Galletta (2013), 'a key benefit of the semi-structured interview is its attention to lived experience while also addressing theoretically driven variables of interest' ( $\mathrm{p}$. 24). In this research, the semi-structured interviews examine the extent to which the existing options in the hitherto implemented projects of the parks and mountainous recreational areas are based on Tehranians' genuine preferences. For this purpose, 130 interviews were carried out in two types of natural setting in the urban and peri-urban areas of Tehran: the linear parks and mountainous recreational areas situated in a neighbourhood featuring a number of rivers. The interviews were carried out mainly in the winter, spring and summer of 2013, between the hours of $10 \mathrm{am}-2 \mathrm{pm}$ and $6 \mathrm{pm}-1 \mathrm{am}$.

\subsection{Design and planning}

As explained by Wang (Groat \& Wang, 2002), 'Research is more a legitimate form of scholarly inquiry than design ... [as a result] efforts should be made to encourage the view that design activity and research activity are of equal value' (p. 107). The concepts of design as analysis and evaluation, design as action research, and design in collaboration with context and environment, as explained by Wang (Groat \& Wang, 2002), further clarify the role of design as a method of conducting research. In this research, design is a key part of the process of analysis while mapping the river and its neighbourhood, and evaluating the neighbourhood context. Design as an action research plays a fundamental role in this study, specifically while making propositions and testing them in the design of the case study river-valley. Subsequently, and in a more coherent sense, the design in collaboration with context and the environment forms the whole reasoning behind the thesis, which integrates analysis of the social and cultural context with the natural landscape.

In this research, Darband river-valley has been selected as an indicative study for design and planning. At the beginning of the design and planning phase of this study, it was found that urbanscale maps of Darband river-valley and its neighbourhoods do not exist. These files, however, were an absolute necessity for the design and planning phase. In order to draw this map in the urban-scale of 1:15000, a plotted JPG file from the GIS Centre was scanned and inserted into AutoCAD software. The researcher then drew the necessary map using this inserted file and information available on Google Earth and Google Maps. To use this map in further steps of the design and planning, the created AutoCAD (DWG) file was inserted into Photoshop software and converted into PSD format. Then, the layer of functions was added to this map and the land-use map was created by the researcher. This process formed the basis from which to provide in-depth analysis of the river scenario over $33 \mathrm{~km}$ (Municipality of Tehran, 2011; Tehran Municipality Information \& Communication Technology Organization, 2011). Integrated with the other abovementioned methods, the final step is to define the design and planning strategies and objectives that respond to the potentials and problems of both the river-valley and the Tehranian residents (in the scale of 1:15000).

\section{Introduction to the context: Tehran}

Tehran has been the capital of Iran since 1794. Since then, it has experienced three historical eras: the Qajar dynasty (1794-1925), the Pahlavi dynasty (1925-1979), and the Islamic Republic 
(1979-present). During these years, the entire area of the city has undergone constant development. The structural and spatial changes to Tehran, in particular since the city became the capital, have resulted in the transformation of an enclosed city; its population has exploded from 15,000 in 1794 to a provincial total of 13 million in 2017, as it has developed into an ever-growing megalopolis (Anvar, 2011; Behzadfar, 2007; Hamidi et al., 1997; ISNA News, 2014; Statistical Centre of Iran, 2017). The following diagrams describe in greater detail the key changes to Tehran and the city's development and expansion.

Figure 1: Tehran and its developments and expansion, and related images

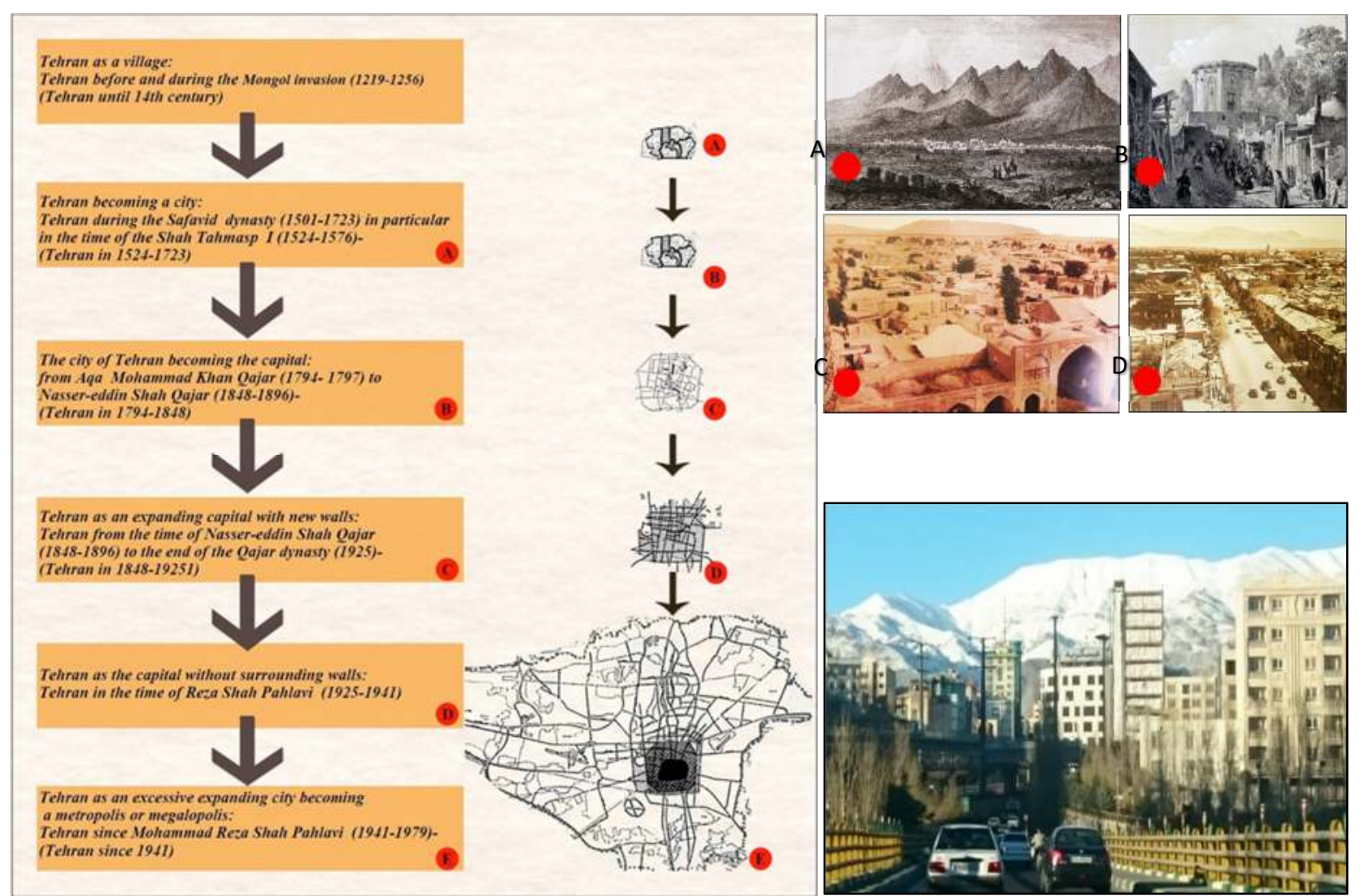

Source of the maps: Anvar, 2011; Behzadfar, 2007; Hamidi et al., 1997. Source of the applied dates: Anvar, 2011; Behzadfar, 2007; Beytooteh Group, 2014; Hamidi et al., 1997; Qazvini, 1275; Sadvandian, 2014. Source of the images: Dubeux, 1841; Flandin and Coste, 1851-1854; Kiani, 2004; Anvar, 2011. Source of the bottom-right image: Author, 2013

As a result of this population growth and the resultant complexities, Tehran has become a melting pot of various groups of residents and immigrants. As further explained by Madanipour (1998), 'Tehran's urban society is an agglomeration of immigrants. It is a mirror of the country as a whole, as Iran is a multi-ethnic and multi-lingual country, ... they have created a mosaic of diverse backgrounds and identities ...' (p. 96).

\section{River-valleys of Tehran: A synthesis of rivers and height differences}

Geographically, Tehran has a special position. Located by the southern slopes of the Alborz mountain, this city has rich resources of water and a mild climate. The slopes of the Alborz provide natural protection against the heat and dryness of the southern deserts. Considering the topography of Tehran, the height difference between the northernmost and southernmost areas reaches around 
$1 \mathrm{~km}$. In this range of height in the north-south direction, the city consists of three sections, including the mountain, foothills (hillsides) and plane lands. This height difference creates visual corridors towards the mountains in different parts of the city. Although the height decreases in the north-south direction, there are some semi-mountainous areas in the southeast neighbourhood area called Bibi Shahr Banoo mountain (Behzadfar, 2007; Hamidi et al., 1997; Mirfendreski et al., 1995; Pasban Hazrat, 2000).

Alborz's presence in the northernmost area of Tehran provides appropriate ground for precipitation and the formation of rich, ever-flowing and continuous rivers. Although some rivers have already been turned into polluted canals of water, others have been used as water sources for industry and agriculture and for drinking water for Tehranian residents (Behzadfar, 2007; Hamidi et al., 1997; Municipality of Tehran, 2015). The combination of rivers and height differences has resulted in the creation of the 'river-valley' in the urban context of Tehran. However, rather than using the term 'combination', the term 'synthesis' is proposed for the river-valleys. This shows the augmentation of potentials as well as the problems associated with the rivers and valleys in comparison to considering them as separate entities.

Tehran has seven major river-valleys; however, opinion differs as to the total number. Running from the easternmost to the westernmost areas of Tehran, the seven main river-valleys are: Sorkheh Hesar, Dar Abad, Darband, Evin-Darakeh, Farahzad (Pounak), Hesarak, and Kan. Since Tehran slopes in the direction of north to south, the river-valleys are mostly parallel, especially in the northern half of the city; this topography causes the water to flow from north to south (Behzadfar, 2007; Hamidi et al., 1997; Ministry of Roads and Urban Development of Iran and Urbanism and Architecture Committee, 2007; Municipality of Tehran, 2011; Tehran Disaster Mitigation and Management Organization, 2014; Tehran Municipality Information and Communication Technology Organization, 2011). The locations of the seven river-valleys on the map of Tehran and the expansion process of the city are shown below.

Figure 2: (Left) The topography of Tehran province in 2006; (right) Tehran province's watersheds in 2006

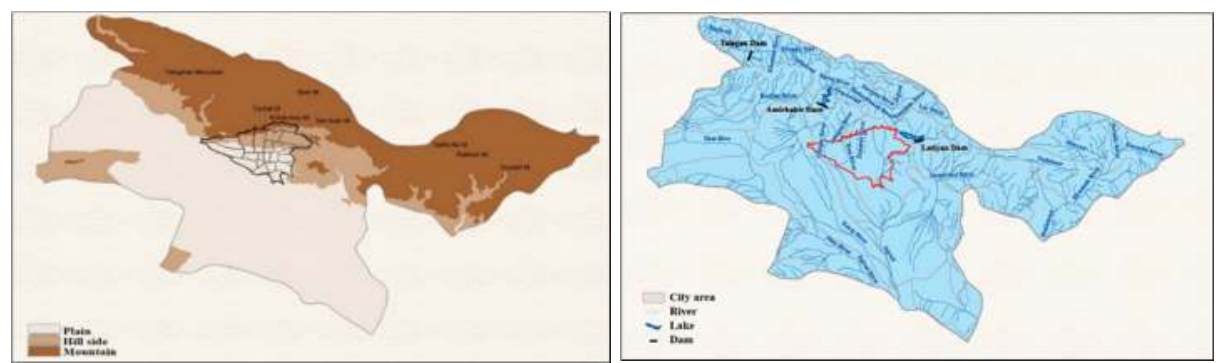

Source of the maps: Tehran Municipality Information and Communication Technology Organization, 2011

Figure 3: Present-day Tehran and the process of the city's expansion since the Safavid dynasty, and the locations of all river-valleys in Tehran; images of the mountains in the northern and southern areas 

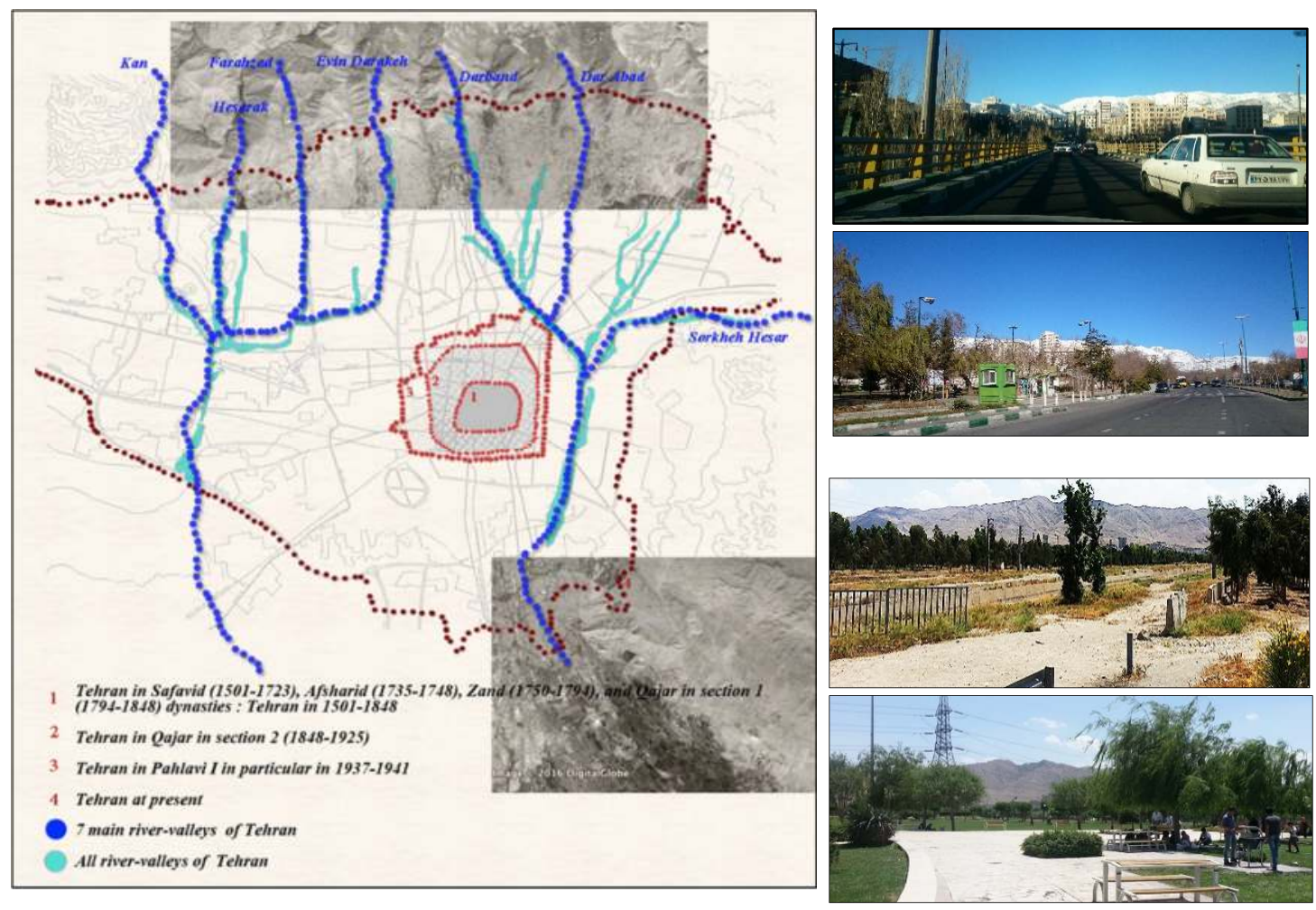

Source of the base maps: Behzadfar, 2007; Hamidi et al., 1997; Municipality of Tehran, 2013; Tehran Municipality Information and Communication Technology Organization, 2011

\section{Hitherto implemented projects in riverside neighbourhoods}

The implemented projects within the seven major river-valleys of Tehran include three linear parks and four mountainous recreational areas. The three linear parks, which were created by the Municipality of Tehran, are based along short lengths of three of the seven river-valleys. These projects include Park-e-Saheli, or Riparian Park, on the Dar Abad river-valley in district 1, Nahjol-Balagheh Park on the Farahzad river-valley in district 2, and Javanmardan-e-Iran Park on the Kan river-valley in districts 5 and 22.

In addition to these three linear parks, there are four recreational areas in the mountainous and semi-urban parts of four river-valleys: Dar Abad, Darband, Evin-Darakeh and Farahzad. These recreational areas are used mostly for mountaineering, hiking and other leisure activities by Tehranians as well as tourists. Dar Abad, Darband and Evin-Darakeh recreational areas are located in district 1, while Farahzad recreational area is situated in district 2 (Municipality of district 1 of Tehran, 2011; Municipality of district 2 of Tehran, 2012; Municipality of Tehran, 2011). The locations of these projects on the map of Tehran and corresponding images are presented in the following figure. 
Figure 4: Locations and images of the linear parks and mountainous recreational areas in Tehran

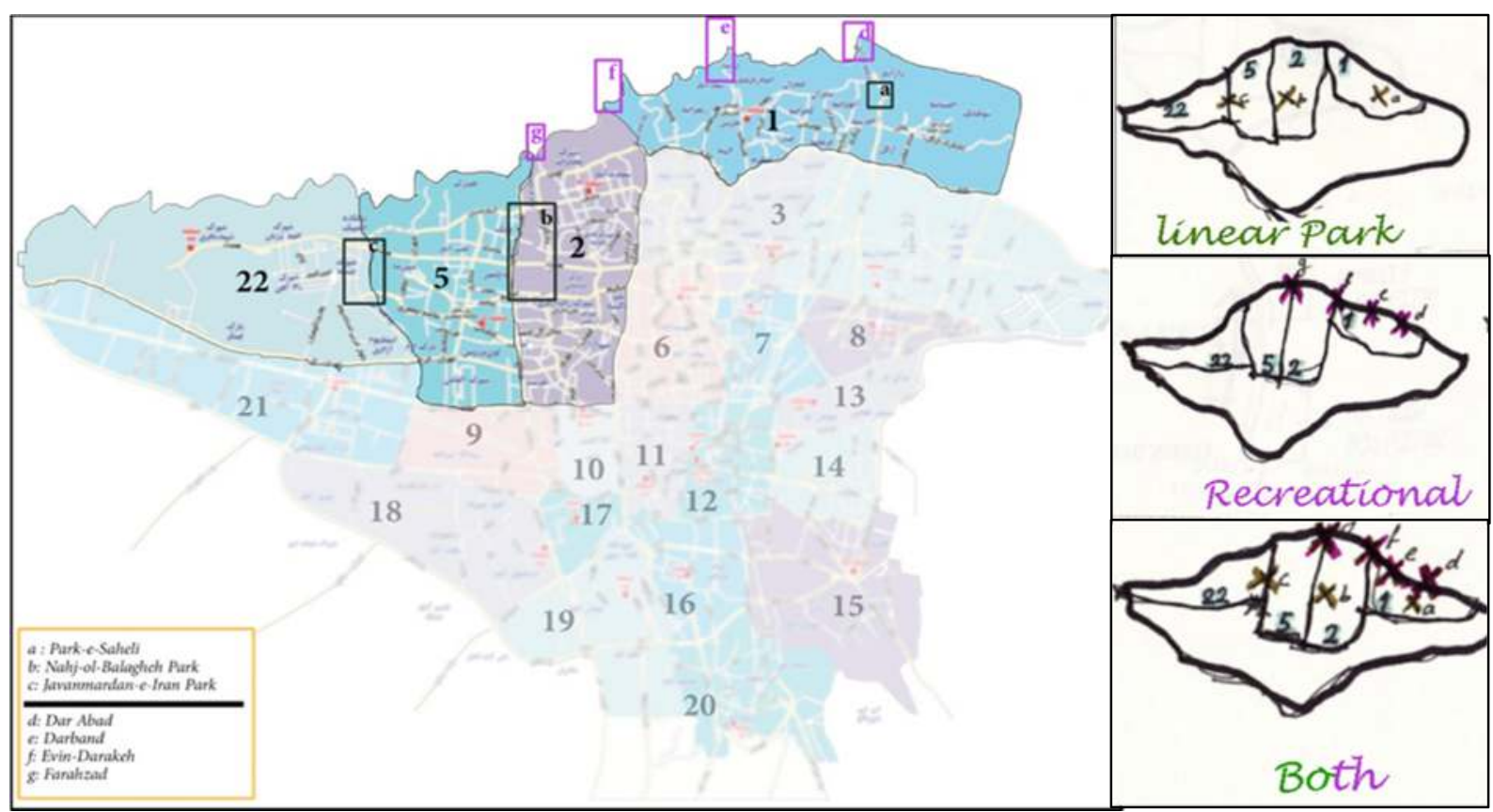

Source of the base map: Municipality of Tehran, 2013. Source of the diagram: Author, 2012

\section{Darband river-valley}

As explained above, no previous studies have investigated how Tehranian residents interact with the existing natural structures of the river-valleys in the implemented projects of the linear parks and mountainous recreational areas. Darband river-valley serves as the design and planning case study for this design-based research. Some of the key characteristics of this river-valley are explained here.

\subsection{River continuity}

Darband river originates from the mountainous areas of north Tehran called Alborz. Although the river flows mostly through a covered and open concrete canal, the water still flows in all urban areas. As a result of passing through urban areas in a north-south direction, the river water loses quality and becomes increasingly polluted. However, the continuous flow of the water provides the opportunity to design the river as a continuous landscape structure. Emerging from the urban context of Tehran, the river reaches three other rivers, the Jajrud, the Kan and the Karaj. The joined rivers - shown as Jajrud on most maps - pass some areas of dry land and desert in central Iran, and move towards the mainly dry land of Salt Lake near the city of Qom (Adib, 2015; Google Maps, 2011; Tehran Municipality Information and Communication Technology Organization, 2011; Tishineh Group, 2015) (see Figure 5). 


\subsection{Height differences and topography}

The height difference within Darband river-valley is around $1 \mathrm{~km}$. In the northernmost sections, the mountainous recreational area attracts Tehranians from all over the city, as well as tourists. Then, in the north-south direction, the river passes through the urban context of Tehran. Reaching the southern limits of the city, the river enters the plane and the deserts of central Iran. However, in the river neighbourhood in the southernmost areas of Tehran, there is a mountain called Bibi Shahr Banoo. The topography and height difference in the north-south direction within Darband river-valley provides the opportunity to create a variety of possibilities in the neighbourhood (Municipality of Tehran, 2015; Tehran Municipality Information and Communication Technology Organization, 2011) (see Figure 5).

\subsection{River junctions}

Flowing from the northernmost to the southernmost areas of the city, Darband river joins eight other rivers in the urban and peri-urban areas of Tehran. Of these eight rivers, Dar Abad and Sorkheh Hesar are of the two other main river-valleys. The confluences create a synthesis of potential as well as problems (Behzadfar, 2007; Tehran Municipality Information and Communication Technology Organization, 2011). Hence, as part of the design and planning strategies for Darband river-valley, it is necessary to study how the region can benefit from the synthesis of potential at the junctions and turn them into opportunities for users. On the other hand, it is necessary to identify the synthesis of the problems and provide responses as part of the design and planning strategies (see Figure 5).

\subsection{Variety of neighbourhood characteristics and gradual changes}

From the northernmost to the southernmost points, Darband river-valley passes through six urban districts of Tehran, including districts 1, 3, 7, 13, 14 and 15. As it leaves the southernmost areas of district 15, the river enters some plan, green, peri-urban lands in the neighbourhood of district 20. As the river passes through these six urban districts, the characteristics of the river neighbourhood gradually changes (Municipality of Tehran, 2015; Tehran Municipality Information and Communication Technology Organization, 2011). Different neighbourhood characteristics mean that there are possibilities to develop diverse design strategies. An example of the impact of gradual changes on the quality of the residential blocks along the river is provided in Figure 5 to further clarify this point. From north to south, the quality of life in the neighbourhood close to the river decreases and the proportion of old and vulnerable textures increases. The term 'quality', here, refers to the subjective and objective indicators of the built environments such as density, compactness, and the characteristics of the residential blocks, as well as health, welfare, living conditions, lifestyle, satisfaction and happiness.

In present-day Tehran, the most expensive high-rises and many newly built and modern residential areas can be found in the northernmost districts of the city and districts 1 and 3 in particular. In contrast, the southernmost areas of Tehran have many poor-quality residential units and many old and vulnerable textures (Ministry of Roads and Urban Development, Urbanism and Architecture Committee, 2007; Municipality of Tehran, 2015; Tehran Municipality Information and Communication Technology Organization, 2011). This reveals that the residents of the river neighbourhoods experience different standards and styles of living. The spectrum of their various needs and expectations necessitates a design process that provides unity as well as variety for the whole river-valley as a continuous landscape structure. 
Figure 5: River continuity, height differences and topography, river junctions, and variety of neighbourhood characteristics and gradual changes

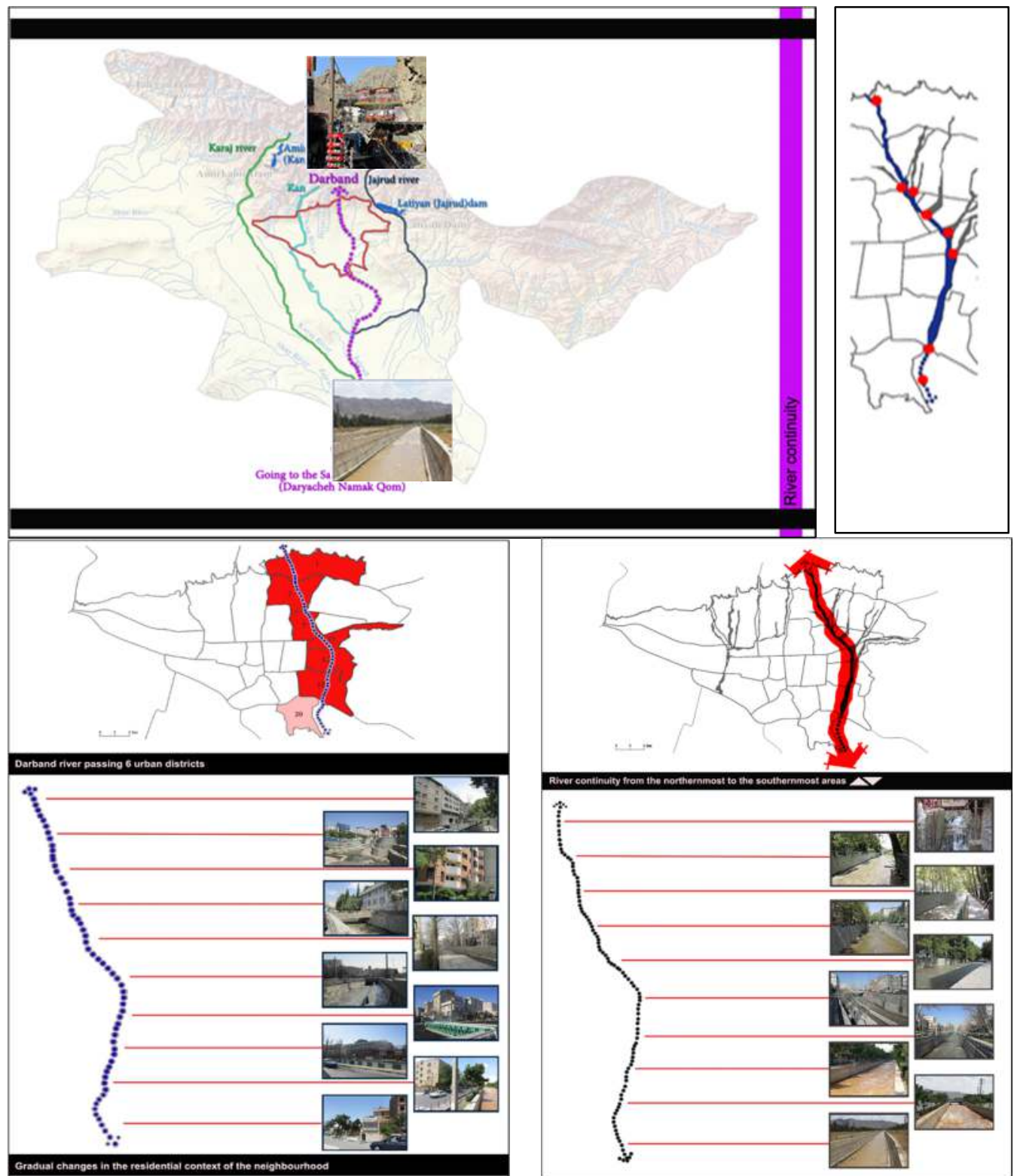

Source of the base maps: Tehran Municipality Information and Communication Technology Organization, 2011. Source of the diagrams and images: Author, 2013

\section{Complementary possibilities for Darband river-valley and Tehranians}

The main characteristics of the context (Tehran) and the features of Darband river-valley and its neighbourhoods have been presented. As the main investigation of this research, this section investigates a series of complementary possibilities for this case study river-valley. The term 'complementary' indicates that the series of design and planning strategies and objectives complement each other in such a way that defines the whole $33 \mathrm{~km}$ length of Darband river-valley as a continuous urban landscape structure. With a main focus on the socio-cultural aspect of sustainability, the series of design and planning proposals in this section form an integrated 
scenario for Darband river-valley in ways that respond to the potentials and needs of both Darband river-valley and Tehranians.

\subsection{Inner-city local and medium-sized parks and the tendency for neighbourhood-scale communication}

The tendency for neighbourhood-scale communication between local residents has existed since the first phases of the development of Tehran as a city in the Safavid dynasty (1501-1723), in particular since the time of King Shah Tahmasp I (1524-1723). In other words, traces of neighbourhood-scale communication have been found in Old Tehran since 1524. Although this tendency still remains, it has been transformed and, hence, represented in other formats in the modern lives of Tehranians (Behzadfar, 2007; Hamidi et al., 1997).

In parks, specifically local and medium-sized parks, for instance, communal morning exercise, the presence of groups of retired men, the presence of non-employed women, evening exercise by families (employed family members and students, in particular) and use at night are examples of the continuing tendency for local interaction with other neighbours as well as with the nature that exists within the parks. In other words, the local or medium-sized inner-city parks play a key role in the neighbourhood-scale routines of modern Tehranians (see Figure 6). As a result, in order to strengthen and develop the possibility of neighbourhood-scale interaction between local residents and nature - particularly in Darband river-valley - through the design and planning process, it is necessary to investigate the areas that have the potential to develop local or medium-sized parks. As explained in the previous sections, to date, no linear, local or medium-sized parks have reflected the river-valley in their designs in any parts of Darband river-valley.

After locating the suitable areas, the next step in the design and planning process for these proposed local or medium-sized parks relates to the use of the river-valley in the designs in order to create human-nature interaction. Applying the water in the designs for the parks in the form of rivers, pools or predetermined streams, or through an integrated system of stationary and flowing water, provides various possibilities for visual, aural and even physical (touch) interaction with the water. A few examples clarify the various possibilities of visual, aural, olfactory and physical interaction with nature at different levels and in different systems of water, as well as activities such as stationary or transit points within the parks: gatherings in areas around a park's central pool to begin morning exercise or communal breakfast with neighbours; local groups of neighbours gathering alongside the river for communal morning exercise; and groups of retired men or families sitting at different pause points at different height levels in the park to enjoy a variety of perspectives of the park and the river-valley (see Figure 6).

In order to create the possibility of mutually supportive interaction between Tehranians and Darband river-valley through the neighbourhood-scale routines in the proposed inner-city green spaces and parks, the general proposed strategies and objectives include maintaining the river continuity and flow of water; applying compatible materials and designs for the river walls, paths and fencing; ensuring that the quality of the water is maintained to a good standard; and defining a suitable number of bridges with designs that are compatible with the existing natural structures as pause points and transit points. These points were analysed in detail through direct observation of the implemented linear parks. 
Figure 6: The role of inner-city parks in the social attitudes of Tehranians as well as human-nature interactions (communal morning exercise and eating breakfast together; groups of retired men; presence of non-employed women, evening use and exercise and use at nights)

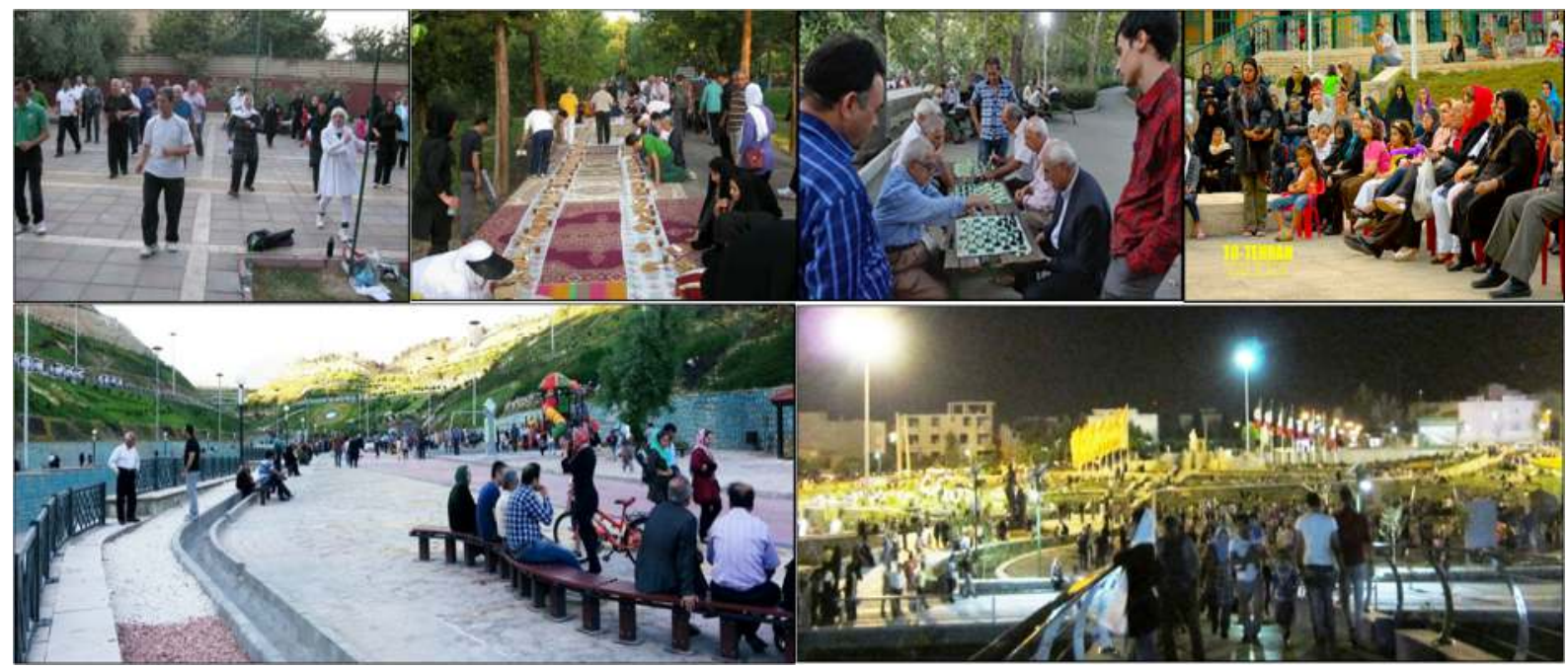

Source of the top images: Ouchizi, 2014; Dana Khabar Group, 2013; To-Tehran Theater Group, 2010

\subsection{Urban spaces of squares and streets and the disappearing history}

\subsubsection{Squares}

On a variety of scales, squares have played a key role in the social and urban lives of Tehran and Tehranians since the primitive phases of the development of Tehran as a city in the Safavid dynasty (1501-1723). However, the concept and designs of the squares were affected in the time of the subsequent dynasties. The arrival of automobiles in 1902, during the late Qajar dynasty (1794-1925), and the transformation of Tehran into an administrative-industrial society in the time of King Reza Shah Pahlavi (1925-1941) were two of the key factors that resulted in the transformation of the designs of public spaces, and in particular the squares and streets (Banimasoud, 2009; Behzadfar, 2007; Soltanzadeh, 2007).

However, beyond the conversion of the objectivity of squares, Tehranians' subjective view of the concept of squares has remained unchanged. While the present automobile-based squares represent the dominance of modernisation and the scale of automobile use on most days, (some of the main) squares are still used as platforms by pedestrians for demonstrations, for specific mourning on days such as Ashura, and for the celebration of particular events. It should be explained briefly that, every year, on the day known as Ashura in Iran and other Islamic countries, a lamentation and public mourning is held for the commemoration of a holy figure in Shia Islam, Imam Husayn. Ashura is held on the tenth day of the month, called Muharram, which is the first month of the Islamic Arabic calendar. Ashura was the day on which the tragic massacre of Karbala took place in $680 \mathrm{CE}$. In this massacre, the prophet's grandson, Husayn, was killed, along with most of his close family members (Banimasoud, 2009; Behzadfar, 2007; Cornell, 2007; Yaghmaei, 2002).

The continuing tendency for the presence of squares in the social and cultural identity of routines and rituals, on one hand, and the gradual disappearance of the pedestrian and human scale in the design of the squares, on the other hand, necessitate the revival of these urban spaces in the public lives of Tehranians. As such, as part of the design and planning process for Darband river- 
valley, it is necessary to identify the points that have the potential to be converted into humanbased squares.

The river's junctions and the existing well-known squares along the path of the river, such as Tajrish Square - the most famous square in the northern area of Tehran - are two of the key types of area that have the potential to be converted to human-based squares. While the proposed humanbased squares can be a part of the social and cultural identity of Tehranians in everyday life and on specific days, the presence of nature in these squares can result in human-nature interaction through routines and rituals. As a design strategy for the proposed squares, pedestrians could be prioritised in the use of car-free policies, and predetermined points for water in these squares could be specified. A combination of water in running and stationary forms can provide the possibility of conscious or subconscious interaction with water for the users of the squares as they engage in their preferred activities (see Figure 7).

Figure 7: Examples of current squares along the path of Darband river-valley and the potential for creating humanbased squares at the river junctions in ways that provide human-nature interaction as well as responding to the social attitudes of Tehranians (in the image: n.3: Tajrish Square)
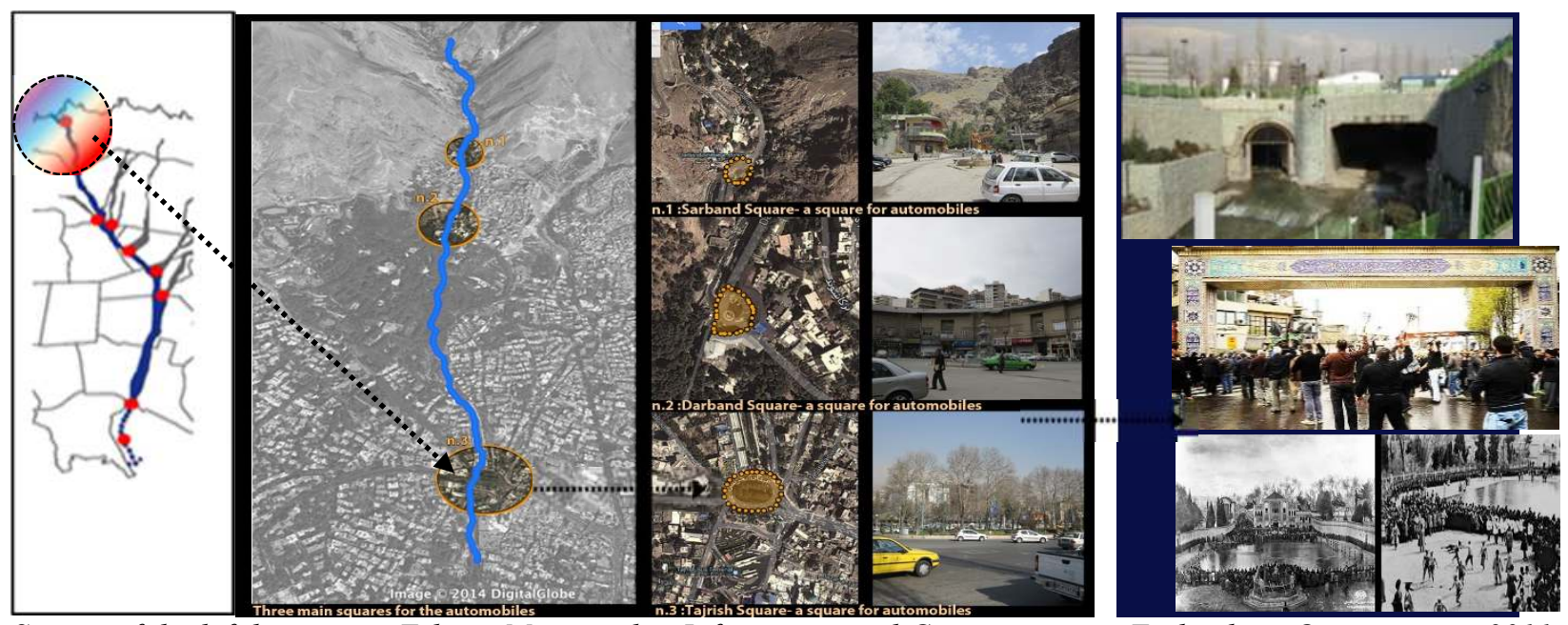

Source of the left base map: Tehran Municipality Information and Communication Technology Organization, 2011. Source of the middle base map: Google Maps, 2011. Source of the top image: Author, 2013. Source of the right-middle image: Jalilzadeh, 2014. Source of the right-bottom images: Golestan Palace Organization, 2014; Municipality of Tehran, 2016. Source of other images: Author, 2012-2013

\subsubsection{Streets}

Similar to the squares, the streets have played an important role in the communal and public lives of Tehranians since the early stages of the development of Tehran in the Safavid Dynasty (1501-1723). The role of the streets in the social and cultural identity of Tehran and Tehranians has been strongly affected by various phenomena. These include mainly the introduction of cars in 1902 during the late Qajar dynasty (1794-1925), the demolition of the city's walls (1932-1937) in the time of King Reza Shah Pahlavi (1925-1941), the construction of a piping system for water (1949-1955), and the transformation of Tehran into an administrative-industrial society in the time of King Reza Shah Pahlavi, and, hence, the accelerated development and subsequent expansion of the city as a grid network based on an automobile-based system (Banimasoud, 2009; Behzadfar, 2007; Soltanzadeh, 2007). 
The literature review of Tehran clarified the existence of four types of street in the city. This includes streets in the style of Isfahan, streets in the style of Tehran (Nasseri), streets as bazaars and small bazaars - also known as bazaarcheh - and local neighbourhood-scale streets and alleys. Images of all four street types are presented below to illustrate the existence of users' interaction with nature in the streets of Old Tehran as they carry out the various activities involved in certain routines and rituals (see Figure 8). The images mainly address the side streams and rows of trees on the streets in the styles of Isfahan and Tehran (Nasseri), the central pool and the middle stream in the bazaarcheh, and the middle stream accompanied by sabat in the neighbourhood-scale streets and alleys. It should be explained that a sabat is an arch-shaped indoor or semi-indoor roof in a neighbourhood-scale street that not only protects users in unsuitable weather but also acted as a protective element during invasion in the past. Furthermore, sabats could make gathering points more private for local users (Banimasoud, 2009; Behzadfar, 2007; Keramati, 2006; Soltanzadeh, 2007).

Direct observation and the review of the literature on present-day Tehran showed that the objective role of the streets in the social attitudes of modern Tehranians has begun to disappear. However, the subjectivity of the streets and their tendency for reviving the presence of streets in routines and rituals still remains. This tendency can be traced by considering the presence of some of the main streets of Tehran in demonstrations and celebrations of specific days, or in the present neighbourhood-scale communal interactions of local residents in some of the old neighbourhoodscale streets of south Tehran. Hence, as a design strategy for Darband river-valley, it is necessary to identify the streets and alleys that have the potential to be converted into any of the four aforementioned types of street.

Figure 8: Human-nature interaction in all four types of street in Tehran: streets in the styles of Isfahan and Tehran (Nasseri), streets as bazaarcheh, and local neighbourhood-scale streets and alleys; examples of current streets in the Darband river-valley's neighbourhood and their potential
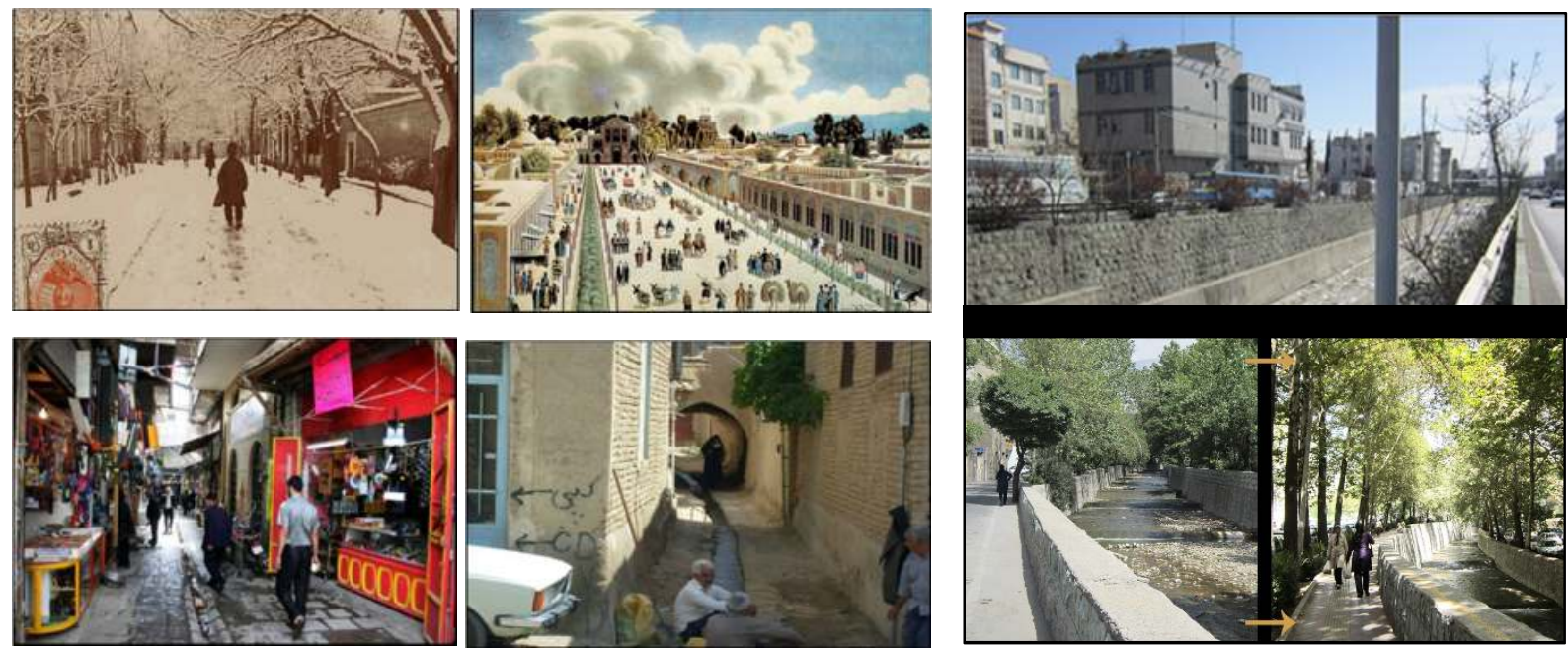

Source of the top-left image: Shahrefarang Group, 2015. Source of the top-middle image: Eshia Organization, 2015. Source of the bottom-left image: Irannema Group, 2015. Source of bottom-middle image: Joshaghan Group, 2015. Source of the top-right and bottom-right images: Author, 2013 


\subsection{Big parks and unconstructed pieces of land and the social attitudes associated with specific days (in southeast Tehran)}

In addition to the semi-mountainous area of Bibi Shahr Banoo in southeast Tehran, there are a number of big parks in the city and some unconstructed pieces of land. The locations of these parks and the direction of possible development for the green spaces are shown in Figure 9. It should be noted that the majority of the proposed design and planning strategies and objectives for small and medium-sized inner-city parks and green spaces - which are discussed in section 7.1 - are applicable to the big parks, green spaces and unconstructed land along the Darband river-valley. However, in order to achieve the complete presence of these areas in the socio-cultural attitudes of Tehranians, it is necessary to define further complementary strategies.

As the interviews showed, the big parks and green spaces have been acknowledged as suitable places for rituals on specific days that have continued since ancient times. These specific days and the social customs and traditions relate mainly to the Persian New Year and its water-based traditions, particularly on the day known as Sizdah-be-Dar. Currently, Norouz is identified as the Iranian New Year, at the spring equinox. Norouz, the biggest national celebration of the start of spring, has special customs and traditions that are dependent on or related to nature. In other words, the traditions of Norouz explicitly or metaphorically represent Iranians' affinity, beliefs and respect for nature. One of these traditions is the preparation of a special table setting, called the Haft Sin. In the Persian language, the word haft means 'seven' and Sin represents the 15th letter of the alphabet (corresponding to the letter S in the English alphabet). Accordingly, the Haft Sin table integrates seven nature-related items that start with the letter S (see Figure 9).

Shortly before the arrival of the New Year, all members of the family gather around this setting and pray for health, prosperity, fortune and happiness. This custom has been held since the time of the Sassanid empire (224-651 AD) in Iran. All items included in the Haft Sin represent health, happiness, prosperity, fertility, long life, love, joy, production, nature and light. The start of Norouz and the first of the month Farvardin in the Persian calendar is usually equivalent to the 20th or the 21 st of March. Currently, Norouz is a 13-day celebration in Iran, and the last day - the 13th day of Norouz and Farvardin - is called Sizdah-be-Dar. In the Persian language, Sizdah means 13, be means 'to', and dar means 'door'; therefore Sizdah-be-Dar means 'staying outside the door'. In other words, it refers to staying outdoors, whether within the city or in the countryside (Bahar, 1994; Campo, 2009; Daniel and Mahdi, 2006; Joneidi, 1979; Massoudi, 2014; Mirafzali, 2009; Razi, 2004; Sheikh Farshi, 2002).

The effect of Zoroastrianism is conspicuous in the symbolism of the rituals of the day of Sizdahbe-Dar. One of the most famous customs of Sizdah-be-Dar is the placing of the sabzeh - one of the key items in the Haft Sin table setting, and is sprouted seeds of grains - into flowing water such as rivers and streams. In other words, sabzeh is taken from the sofreh Haft Sin and thrown into running water, such as a river or stream. Literally, sofreh means a decorative cloth that Iranians spread over a table or over the ground. So, sofreh Haft Sin is a special table setting that Iranians prepare before the New Year, Norouz. Although the story behind this tradition - which originally stems from the civilisation of Mesopotamia and later the Middle East - is unknown by a significant number of Iranians, the custom remains and is observed by the majority of Iranians each year on Sizdah-be-Dar (Razi, 2004; Bahar, 1994; Joneidi, 1979).

In order to maintain and strengthen the customs and traditions of Sizdah-be-Dar, such as placing the sabzeh in flowing water, the interviewees' explained the specific criteria for selecting suitable 
areas. As explained by the majority of the interviewees, the key characteristics of a suitable area for Sizdah-be-Dar include the degree to which the area is natural, the degrees of greenness, vastness and openness (open and flat, green spaces with an abundance of wilderness), access to flowing water such as rivers and streams, the amount of available space and privacy for each family (less overcrowding), ease of access and few or no traffic problems, and calmness and peace. Hence, as a design strategy for potential big green spaces, particularly the potential and existing green spaces of southeast Tehran, the area for the proposed integrated park needs to be developed through a more natural and undesigned landscape formation to provide sufficient access to the flowing water of Darband river.

Figure 9: (Left) The role of large parks with open and green spaces in the social attitudes of Tehranians in southeast Tehran, and the variety of possibilities in southeast Tehran: mountainous area, unconstructed land and green areas, and big parks; (right) social rituals and customs associated with Sizdah-be-Dar
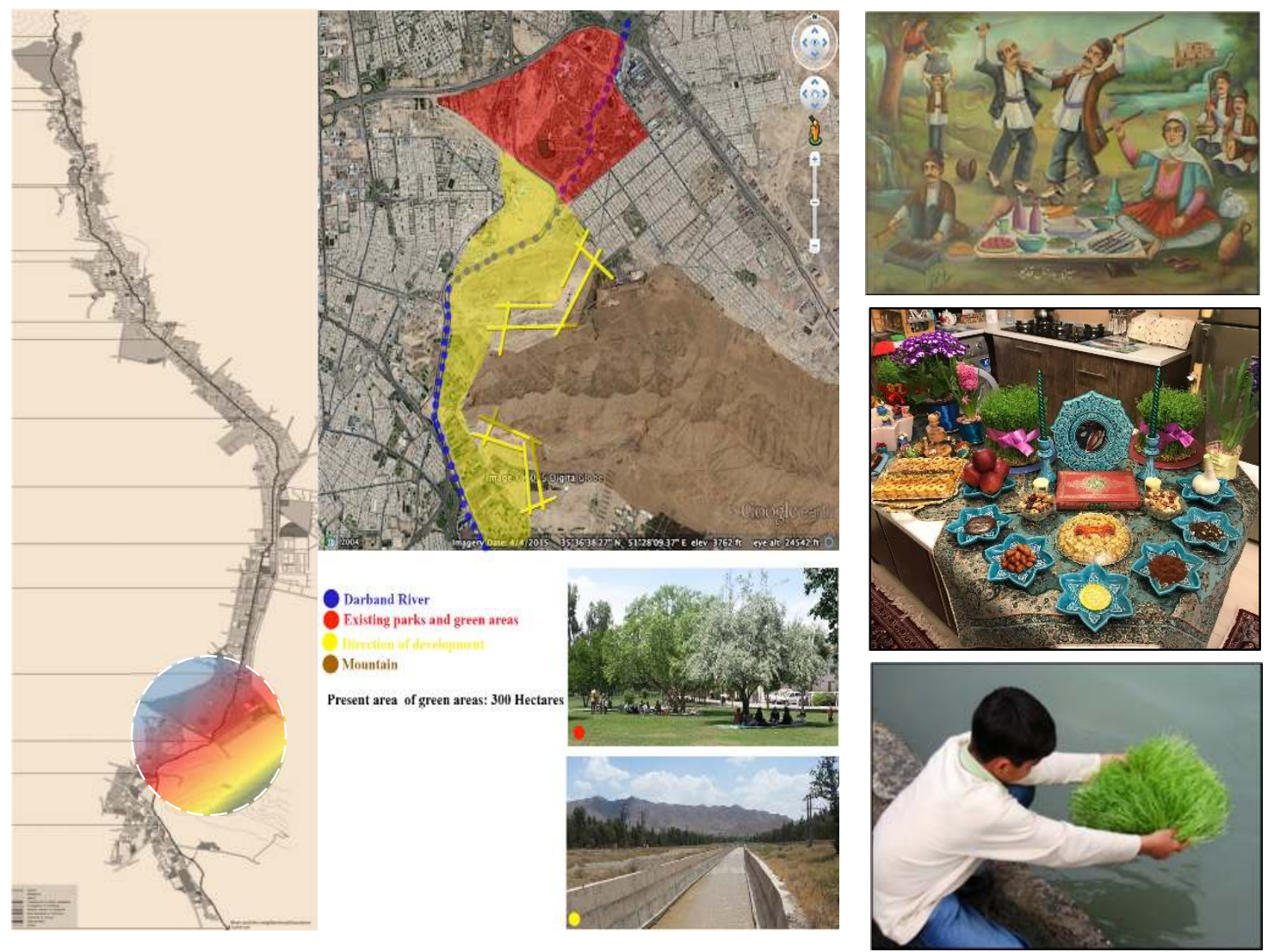

Source of the middle base map: Google Maps, 2011. Source of the top-right image: Javanfa Group, 2015. Source of the bottom-right image: Maroozi, 2013. Source of the left map, diagram and other images: Author, 2013-2017

\subsection{Mountainous recreational areas: mountainous areas of north Tehran, and mountainous and semi-mountainous areas of southeast Tehran}

As explained above, in present-day Tehran, the northernmost areas of Darband river-valley are recognised as mountainous recreational areas with traditional restaurants and cafes. In the southernmost areas of Darband river-valley, there are some plane lands. The semi-mountainous and mountainous areas of Bibi Shahr Banoo are situated further away from the river, in southeast Tehran. Although the northern areas of Darband river-valley have been recognised as key recreational destinations for Tehranians, there are no recreational facilities in southeast Tehran. 
The tendency of maintaining and strengthening the existing mountainous recreational areas in the northernmost areas of Darband river-valley was revealed in the interviews. However, the interviews revealed that Darband mountainous area (in the northern area) has problems with overcrowding, and also traffic and parking challenges. These two issues reveal the accumulation of mountainous recreational facilities at only one point of Darband river-valley (north Tehran), rather than an even distribution throughout the existing mountainous and semi-mountainous areas of south and north Tehran. As such, the distribution of mountainous and semi-mountainous recreational areas (in southeast and north Tehran) is proposed as a design and planning strategy for Darband river-valley. In the existing and potential mountainous and semi-mountainous areas, the whole area is defined by meandering and rocky mountaineering paths with recreational facilities such as restaurants, cafés and vendors. In other words, the facilities that generate feelings of excitement, energy, enjoyment, recreation and enthusiasm have already shaped the identity of the mountainous areas, as well as a significant part of the identity of Tehranians (see Figures 9 and 10).

According to the direct observation and interviews, in these existing and proposed mountainous and semi-mountainous recreational areas of southeast and north Tehran, the proposed design and planning strategies and objectives that could improve the possibility and quality of the interaction between Tehranians and the river-valley include maintaining the river continuity and the flow of water; applying contextual materials such as mountain rocks as river walls, paths and fencing; ensuring that the quality of the water is maintained to a good standard; defining suitable bridges as pause points and transit points; and defining adequate parking facilities in accordance with the number of visitors. These strategies and objectives are not only based on improving the quality and extent of conscious or subconscious interaction with the nature within the areas while visitors are in them; they are also based on the main reasons that some users' express for coming to the area.

Figure 10: Mountainous recreational areas in the northern areas and the absence of mountainous recreational facilities in the southern areas of Tehran
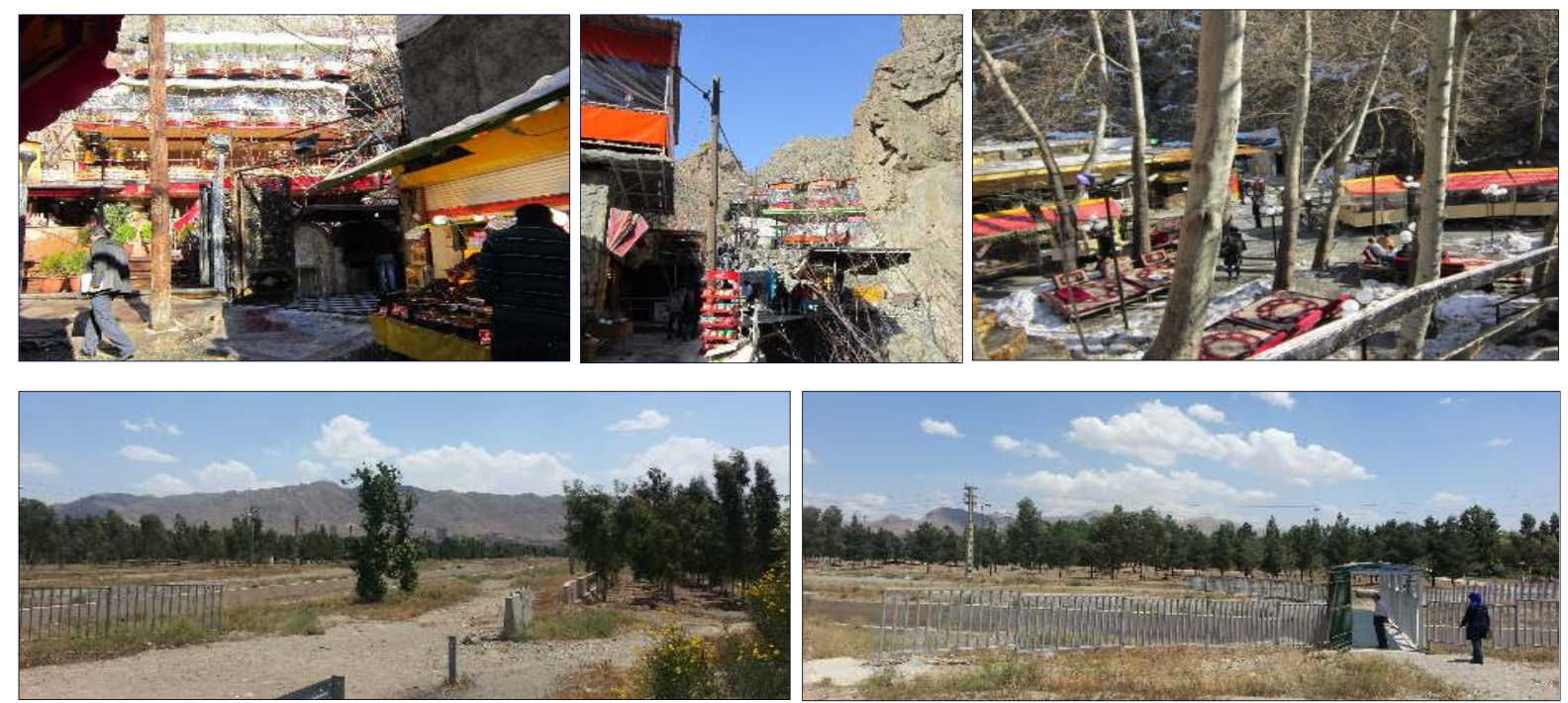

Source of the images: Author, 2012-2013 


\subsection{Bridges as landscape in transit as well as pause points}

The tendency of maintaining and strengthening the role of bridges in the routines of citizens was revealed through direct observation of the bridges in the implemented projects within the linear parks (see Figure 11). Furthermore, in the design of the proposed and existing natural areas (including the local and medium-sized parks, the big parks with wider open spaces, and the mountainous and semi-mountainous recreational areas, as well as the four types of street discussed above), creating connections between the two sides of the river is necessary. In order to respond to this tendency in the design and planning of Darband river-valley, it is necessary to define the required number of bridges, to predetermine specific points over the river at which to locate these bridges, and to use compatible and contextual designs for the bridges. These implicit design objectives are necessary to achieve the strategy of developing a landscape in transit as well as at pause points along the path of Darband river-valley. Furthermore, creating adequate connections between the two sides of the river-valley is a necessary design objective that plays a part in forming physical perceptions of the river and physical perceptions of the height difference in the valley (Pakzad, 2008; Paumier, 2004; West 8, 2014).

It is necessary to define bridges as pause points as well as for connection in order to revive the social and cultural characteristics of the bridges and, simultaneously, of the rivers in urban life. The necessity of defining these bridges becomes more significant when considering that, at present, there are no designed bridges over Darband river, even in the mountainous recreational area of Darband in north Tehran. In other words, the present undesigned bridges over Darband river are used merely as connecting paths between the two sides of the river-valley without any consideration for the routines of citizens.

Figure 10: (Left) Current bridges over Darband river-valley; (right) example of potentials to create landscape in transit as well as pause points over river-valleys (a bridge in Javanfmardan-e-Iran Park in the Kan river-valley)
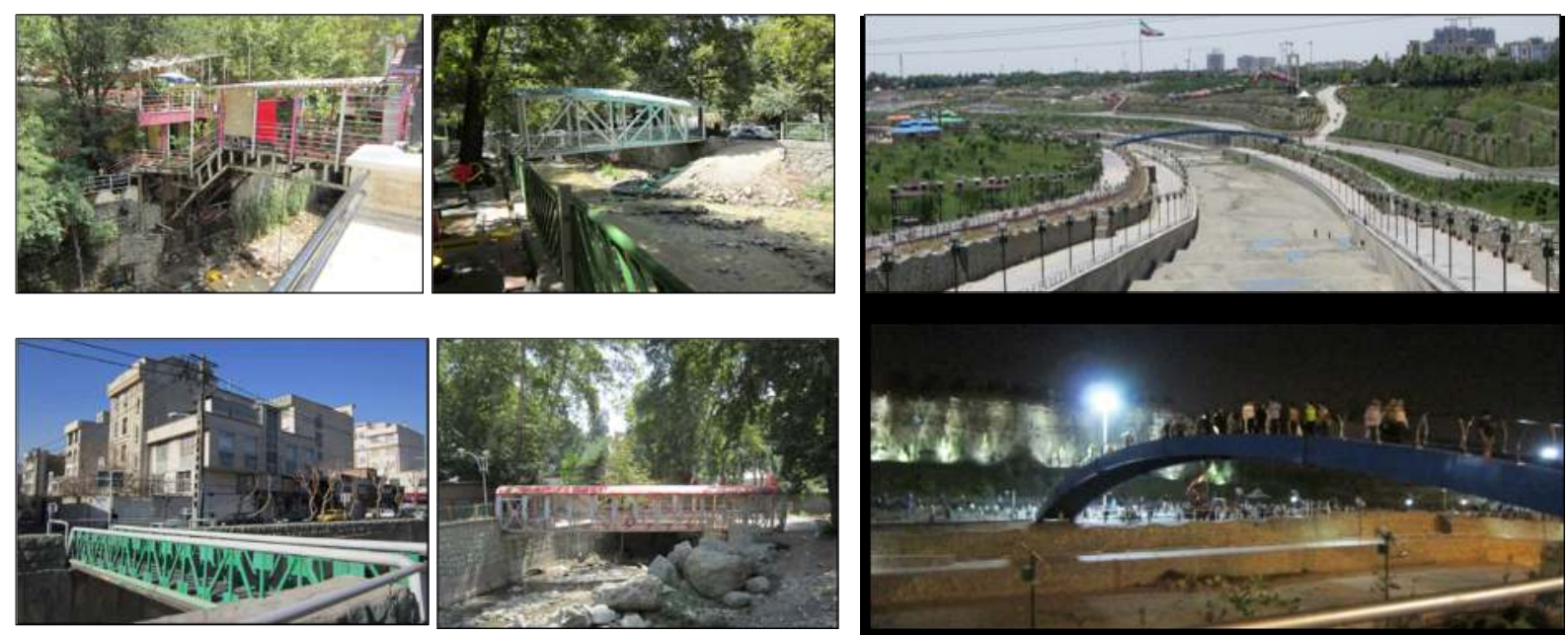

Source of the images: Author, 2012-2013

\section{Conclusion}

In the global context, the continuous development and expansion of cities has resulted in the conversion of 'natural structures' that were outskirt cities into urban landscape structures, also known as 'landscape structures of cities'. As such, these landscape structures need to be studied in top-level and urban-scale decision-making projects for cities. While the integration of 'landscape' 
and 'urban' aspects creates a potential synthesis of opportunities, it can result in an augmentation of problems and challenges. Therefore, the aim of this research was to study how best to make use of the natural structures of cities in a way that results in a mutually supportive human-nature interaction. Such a complementary relationship between human beings and nature would respond to the needs, potentials and problems of both spheres and thus lead to achieving sustainability in the full sense of the concept. The selected case study for this human-nature interaction in the urban context was the city of Tehran and the natural structures of the river-valleys, with a focus on Darband river-valley.

Darband river-valley, with a length of $33 \mathrm{~km}$ and a height difference of $1 \mathrm{~km}$ in the urban and peri-urban areas, passes from the northernmost to the southernmost areas of Tehran. It starts from the mountainous areas of the north, called the Alborz, passes through six urban districts with varying characteristics and quality of life, then enters the plane lands and finally the deserts in the southeast area of Tehran. Further away from the river, in the southern areas, there is a semimountainous area called Bibi Shahr Banoo. The main implemented project over this $33 \mathrm{~km}$ includes the mountainous recreational area in the northernmost areas. In other areas, however, the rivervalley has not been reflected in the design and planning of any projects, except the mountainous recreational areas of north Tehran. In the urban areas, the river flows mostly in a covered and open concrete canal; reaching the peri-urban areas in the south, the river-also known as a canal-passes some of the big parks and then moves towards the dry lands of central Iran.

In order to convert Darband river-valley into a continuous landscape structure with the possibility of win-win human-nature interaction along the whole of its $33 \mathrm{~km}$ path, a continuous and complementary scenario of possibilities has been proposed in this paper. This spectrum proposes the distribution of mountainous recreational facilities in the southern and northern areas (section 7.5). Defining targets for recreation at the starting point in the northern areas and the end point of Darband river-valley in the southern areas necessitates the continuity of the river-valley as a whole. Throughout this continuum, consideration and reflection of the river-valley in urbanscale landscape projects is necessary. As a result, the complementary scenario suggested in this paper proposes the integration of Darband river-valley with the design of existing and potential local-to-large-sized parks in the urban and peri-urban areas of Tehran. The parks provide the possibility of human-nature and human-human interaction on a variety of scales - from neighbourhood to urban - throughout the routines associated with everyday life as well as specific days in the Iranian-Tehranian context (sections 7.1 and 7.3).

In addition to top-level urban-scale landscape projects for the mountainous recreational areas and parks, the river-valley has the potential to become integrated in the design of urban spaces. Squares, streets and bridges in different locations and on different scales along the path of Darband river-valley and how these urban spaces can provide human-nature interaction have been discussed in detail in this paper. In the complementary scenario suggested in this paper, a reflection of the concept of landscape in transit as well as pause points has also been proposed. This would create a spectrum of possibilities for interaction with the river-valley through an integrated system of stationary and flowing water.

It can be summarised that the proposed complementary possibilities for human-nature interaction in the case study of Darband river-valley for Tehranian residents include five categories. These categories are inner-city local and medium-sized parks and the tendency for neighbourhood-scale communication; urban spaces of squares and streets and the disappearing 
history; big parks and unconstructed pieces of land and the social attitudes associated with specific days; mountainous recreational areas; and bridges as landscape in transit as well as pause points.

It should be noted that, in addition to the aspects discussed, Darband river-valley has the potential to be involved in the routines and rituals of Tehranian residents from several other aspects. This is dependent on the specific detailed characteristics of the river neighbourhood and its neighbourhood residents and how they differ from one specific location to another. This would thus open a new investigation platform for further research to break down the scale of study from urban to neighbourhood and then provide full details of investigation on neighbourhood-scale characteristics of the river-valley. In an ideal platform of investigation, this top-down research and further potential bottom-up approaches would complement each other and thus provide a full list of design and planning strategies and objectives that could lead to sustainability in the full sense of the concept.

\section{References}

Adib, M. (2015). Masileh Salt Lake. [Online]. Iran Deserts Group. Available: http://www.irandeserts.com.

Anvar, A. (2011). Preface. In: Norouzi Talab, H. R. (ed.) Tehran (Past \& Present): The Heritage of Old Tehran. Tehran: Yassavoli Publications, pp. 12-40.

Bahar, M. (1994). Queries in Iran's Culture. Tehran: Fekr e Rooz.

Banimasoud, A. (2009). Iranian Contemporary Architecture. 2nd ed. Tehran: Honar-e-Memari-eGharn.

Behzadfar, M. (2007). Case-Study: Tehran, The Identity of City. Tehran: Nashr-e-Shahr.

Beytooteh Group (2014). The History of Iran. [Online]. Beytooteh Group - the Section of Art and Culture. Available: http://www.beytoote.com/art/negah-gozashte/iran-history.html.

Campo, J. E. (2009). Encyclopedia of World Religions: Encyclopedia of Islam. New York: Facts on File, Inc.

Cornell, V. J. (ed.) (2007). Voices of Islam. London: Praeger.

Dana Khabar Group (Dana News) (2013). Life after Retirement. [Online]. Dana News - Health Section. Available: http://danakhabar.com/fa/news/1154562.

Daniel, E. L. and Mahdi, A. A. (2006). Culture and Customs of Iran. Westport, Conn. London: Greenwood Press.

Dubeux, L. (1841). La Perse. Paris: Firmin Didot Frères.

Eshia Organization (2015). Bab-e-Homayoon Street in Old Tehran. [Online image]. Eshai Organization (Eshia Group). Available: http://images.lib.eshia.ir/images/books/23019/madkhal_66 1_1249619103.jpg.

Finn, J. A. (2005). Getting a PhD: An Action Plan to Help Manage Your Research, Your Supervisor and Your Project. London: Routledge.

Flandin, E. and Coste, P. (1851-1854 (Approximate)). Voyage en Perse de mm. Eugène Flandin, peintre, et Pascal Coste, architecte, entrepris par ordre de $m$. le ministre des affaires 
étrangères, d'après les instructions dressées par l'Institut. Publié sous les auspices de m. le ministre de l'intérieur. Paris: Gide et J. Baudry.

Galletta, A. (2013). Mastering the Semi-Structured Interview and Beyond from Research Design to Analysis and Publication. New York and London: New York University Press.

Golestan Palace Organization (2014). Historical Photos of the Arq Area in Old Tehran. [Online image]. Golestan Palace Organization: The Section of Virtual Tour. Available: http://golestanpalace.ir/vvisit/historicalpic.html.

Google Maps (2011). Tehran, Iran (detail) Map. [Online]. Available from: https://www.google.co.uk/maps/@35.6835556,51.3790918,11z.

Groat, L. and Wang, D. (2002). Architectural Research Methods. New York; Chichester: Wiley.

Hamidi, M. et al. (1997). Structure of Tehran. Tehran: Technical and Engineering Consulting Organization of Tehran.

Irannema Group (2015). Grand Bazaar of Boroujerd which Became Significantly Destroyed in the War. [Online image]. Irannema Group. Available: http://www.irannema.com/v/9548/html.

ISNA News (2014). The Proportion of the Capital (Tehran) in Population of Iran. [online] ISNA News. Available: http://www.isna.ir/fa/news/93021007033/56.

Jalilzadeh, T. (2014). Tajrish in Ashura. [Online image]. Basij Press. Available: http://basijpress.ir/fa/newsdetails/38744.

Javanfa Group (2015). Sizdah-be-Dar in Old Time, Painting by Fathollah Gholar. [Online image]. Javanfa Group. Available: http://www.javanfa.ir/post/19864/94.

Joneidi, F. (1979). Zarvan, Chronology in Ancient Iran. Tehran: Boniad e Neishabour.

Joshaghan Group (2015). Introduction of an Old Alley. [Online image]. Joshaghan Group. Available: http://www.joshaghan-kashan.ir/fa/111.

Keramati, G. (2006). The Role of Water in Iranian City (Past and Present). In: B. Shirazi, ed. The Third Conference of Architecture History and Urbanism of Iran. Bam, Kerman. 25-29 March 2006. Tehran: Cultural Heritage, Handicrafts and Tourism Organization of Iran, 2006, 1-34.

Kiani, M. (2004). Transformation of Concepts and Formation of a New 20-Year Old Contemporary Architecture (1921-1941). Tehran: Institute for studies of Iran's contemporary history.

Madanipour, A. (1998). Tehran: The Making of a Metropolis. Chichester: John Wiley.

Maroozi, E. (2013). The Customs of Sizdah-be-Dar. [Online]. Mehr-e-Mihan Group: An Iranian Culture Media. Available: http://www.mehremihan.ir/iranian-traditions/841.

Massoudi, C. (2014). Land of the Turquoise Mountains: Journeys Across Iran. London: I. B. Tauris \& Co. Ltd.

Ministry of Roads and Urban Development of Iran and Urbanism and Architecture Committee (Ministry of Housing and Urban Development) (2007). Strategic-Structural Plan of Tehran and the Development (Comprehensive Plan of Tehran-2007). [Online]. Ministry of Housing and 
Mirafzali (Andalibi), G. (2009). The Mystery of the Haft-Seen. 2nd ed. Ketab Corp.

Mirfendreski, M. A. et al. (1995). Proposed Project Report for Revival of Alborz (Koohsaran) Valleys in Tehran Metropolis. Tehran: Municipality of Tehran.

Municipality of district 1 of Tehran (2011). About the District one of Tehran: Introduction, History and Features. [Online]. Municipality of district 1 of Tehran (Affiliated to Municipality of Tehran). Available: http://region1.tehran.ir/Default.aspx?tabid=150.

Municipality of district 2 of Tehran (2013). About the District two of Tehran. [Online]. Municipality of the District two of Tehran (Affiliated to Municipality of Tehran). Available: http://region2.tehran.ir/Default.aspx?tabid=534.

Municipality of Tehran (2011). Living in Tehran: The Environment. [Online]. Municipality of Tehran. Available: http://www.tehran.ir/Default.aspx?tabid=118.

Municipality of Tehran (2013). The Map of 22 Districts of Tehran. [Online]. Municipality of Tehran. Available: http://region13.tehran.ir/portals/0/Test/tehran-map-naghshe-iranmantaghe-shahrdary.png.

Municipality of Tehran (2015). Living in Tehran: About Tehran. [Online]. Municipality of Tehran. Available: http://www.tehran.ir/Default.aspx?tabid=117.

Municipality of Tehran (2016). Arq (Arg) Square in Old Tehran. [Online image]. Municipality of Tehran-Tehran Virtual Tour Section. Available: http://virtualtour.tehran.ir/DnnArticle/view/tabid/71/ArticleId/55/.aspx.

Ouchizi, K. (2014). Morning Exercises in Golsar Park. [Online image]. Koosha Group. Available: http://kooshagroup.persianblog.ir/post/37l.

Pakzad, J. (2008). Design Guide Book for Urban Spaces of Iran. 3rd ed. Tehran: Ministry of Housing and Urban Development (Ministry of Roads and Urban Development), Urban Planning and Architecture Vice-Directorate, Secretariat of the Urban Planning and Architecture Higher Council of Iran.

Pasban Hazrat, G. (2000). River-valleys of the cities in Iran: A context of integration of human beings, city and nature. Iranian Journal of Architecture and Urbanism, vols.58-59, no.9, pp. 56-61.

Paumier, C. (2004). Creating a Vibrant City Center: Urban Design and Regeneration Principles. Washington: The Urban Land Institute.

Qazvini, Zakaria Ben Mohhamd Ben Mahmud (1275). Issues of Lands and News of People Translated from Arabic to Persian by J. Mirza Qajar, and Revised and Complemented by M.H. Mohaddes (1994). Tehran: Amir Kabir.

Razi, H. (2004). Ancient Iranian Festivals: Norouz, Abpashan, Abrizgan with the Religious Ceremonies and Customs of Zarathushtrian/ Parses. Tehran: Behjat.

Sadvandian, S. (2014). The Story of Modernity in Iran. [Online]. Institute for Iranian Contemporary Historical Studies - the Section about Transformation of Tehran. Available: http://www.iichs.ir/News-1/(1).

Shahrefarang Group (2015). Alaoddoleh Street in Tehran in the Year 1910. [Online image]. Shahrefarang Group. Available: http://shahrefarang.com/tehran-ferdowsi-avenue/. 
Sheikh Farshi, F. (2002). Anahita in Ancient Iranian Beliefs. Tehran: Horoufieh Publishing.

Soltanzadeh, H. (2007). Urban Spaces in the Historical Texture of Iran. 3rd ed. Tehran: Cultural Research Bureau of Iran.

Statistical Centre of Iran (2017). General Information of Tehran Province in 2017. [Online]. Statistical Centre of Iran - Management and Planning Organization. Available: http://www.mpo-es.ir/Dorsapax/userfiles/Sub1/g_sarshomari95.pdf.

Tehran Disaster Mitigation and Management Organization (TDMMO) (affiliated to Municipality of Tehran) (2014). Mountaineering Paths of the North Tehran. [Online]. Tehran Disaster Mitigation and Management Organization. Available: http://tdmmo.tehran.ir/Default.aspx?tabid=146\&ArticleCategory=156\&smid=531.

Tehran Municipality Information and Communication Technology Organization (2011). Atlas of Tehran Metropolis. Tehran: Tehran Municipality Information and Communication Technology Organization.

To-Tehran Theater Group (2010). Moments of the Performances of To-Tehran Theater Group. [Online image]. To-Tehran Theater Group - Tehran Performances. Available: http://totehran.blogfa.com/post-112.aspx.

West 8 (Urban Design and Landscape Architecture Firm) (2014). Sagrera Linear Park in Barcelona, Spain designed by West 8 (in 2011). [Online]. West 8. Available: http://www.west8.nl/projects/parks/sagrera_linear_park/.

Yaghmaei, S. (2002). Transformation of the Concept of Urban Space in Arg (Arq) Square in Tehran in 1920-1940. Architecture and Culture. Year 5 (15-16), pp. 86-91.

8. 